\title{
Relevance of mast cell infiltration in well-differentiated oral squamous cell carcinoma in biopsy specimen
}

\author{
${ }^{*}$ SN Karim¹, P Biswas², ABMI Hossain³ ${ }^{3}$ AFM Saleh4, MNN Sayem ${ }^{5}$
}

\begin{abstract}
Oral cancer is very common worldwide. More than $90 \%$ of all oral cancers are squamous cell carcinoma (SCC). The molecular biological markers of oral SCC have been extensively studied to aid in prevention and prognosis. However, no marker has been universally accepted so far. Mast cells are important component of cancer stromal interaction. Their early recruitment in tumor microenvironment and multifarious function make them a burning topic of interest in the field of research. So mast cell may act as a new target for the adjuvant treatment of oral SCC. Therefore, the aim of the study was to assess the number of mast cell infiltrations in well differentiated oral SCC. In this cross-sectional study the sample size was 66. After routine tissue processing and staining with Hematoxylin \& Eosin $(\mathrm{H} / \mathrm{E})$ stains slides of all cases were grouped as well differentiated oral SCC. Identification of mast cell was done by Toluidine blue stain. Distribution of mast cells was observed and number of mast cells was counted. The data was tabulated and statistical analysis was performed. The number of mast cell was highly increased in all cases of oral SCC than normal. The mean \pm SD number of mast cells was 3.28 \pm 1.21 in oral SCC, whereas in control oral tissue it was $0.44 \pm 0.19$. The $p$-value was found to be highly significant $(p<0.001)$. So, in our observation mast cell is a good cellular indicator of tumorigenesis.
\end{abstract}

\section{Introduction}

Oral cancer is the sixth most common cancer in the world. ${ }^{1}$ More than $90 \%$ of all oral cancers are squamous cell carcinoma. ${ }^{2}$ It may affect any anatomic site in the mouth such as buccal mucosa, tongue, floor of mouth, gingiva, lip, hard palate, soft palate and retro-molar region. For many years, the five years survival rate of patient with oral SCC has not changed despite improvement in diagnostic techniques and treatment modalities. However, the incidence and prevalence are increasing particularly in younger patients. ${ }^{3}$

There is a marked variation with regard to incidence and mortality from oral SCC between different countries and different geographic locations. The highest incidence rate is found in developing nations situated in South Asia like India, Pakistan, Bangladesh, Taiwan and Sri Lanka. ${ }^{4}$ In Bangladesh the incidence rate of oral cancer is very high.

01. Dr. Syeda Noorjahan Karim, Assistant Professor, Department of Pathology, Gazi Medical College, Khulna.

Email: noorjahanska@gmail.com

02. Dr. Prasun Biswas, Lecturer, Department of Pathology, Mymensingh Medical College, Mymensingh.

03. Dr A B M Iftekhar Hossain, Lecturer, Department of Pathology, Dhaka Dental College, Dhaka.

04. Professor Dr. AFM Saleh, Professor and Ex-Head, Department of Pathology, Mymensingh Medical College, Mymensingh.

05. Md. Noor Nabi Sayem, Data Analyst. 
Here, the number of new cancer cases is about 200,000 per year, of which, oral cancer represents $20 \% .^{5}$ Here oral cancer ranks as second and third in prevalence respectively among male and female population. ${ }^{6}$

The important risk factors for oral SCC are smoking, use of tobacco, alcohol, betel quid and areca nut. Low socioeconomic status, diet low in nutritional values, poor oral hygiene and viral infection such as Human Papilloma Virus (HPV) also contribute towards the risk. ${ }^{4}$

The process of tumor genesis involves interaction between genetically altered malignant cells and surrounding non-neoplastic cells. Tumor cells produce multiple mediators for inflammatory cells. These mediators are responsible for infiltration of immune and inflammatory cells in solid tumors. Among these inflammatory cells mast cell is an important member. ${ }^{7}$

Mast cells are bone marrow derived tissue-homing leukocytes. They are round or elongated cells with a diameter ranging between 8 and $20 \mu \mathrm{m}$ and are easily diagnosed by light microscopy for their toluidine blue positive metachromatic granules that fill the cytoplasm. Mast cells represent a rich source of biologically active mediators which are either preformed in their granules or synthesized de novo. Preformed mediators are histamine, heparin, proteoglycans and proteases. Newly formed mediators include leukotrines and prostaglandins. Mast cells carry an array of adhesion molecules, immune response receptors and other surface molecules, which permit them to react to multiple specific and non-specific stimuli. This wide range of biological function, ubiquitous distribution and strategic location near blood vessels, nerves, inflamed tissues and neoplastic foci enable mast cells to play a central role in a multitude of physiologic, immunologic and pathologic processes. Recently, apart from their roles in the maintenance of homeostasis and in inflammation, their association with various tumors has been described. ${ }^{7,8}$ In several malignancies, mast cell density has been found to correlate to increased risk of metastasis and poor prognosis. ${ }^{9-12}$ Several studies describe that there is a significant role of mast cell mediators in oral SCC. ${ }^{13-21}$

Mast cells are involved in genesis of tumor through four mechanisms: 1) Angiogenesis, 2) Immunosuppression, 3) Degradation of extracellular matrix and 4) Release of growth factors. 14

Mast cells are attracted to tumor context by stem cell factor (SCF) secreted by tumor cells. The receptor for SCF is known as c-Kit, present on the surface of mast cell. Mast cell produces several potent angiogenic factors such as histamine, chymase, vascular endothelial growth factor (VEGF), fibroblast growth factor -2 (FGF-2), transforming growth factor $\beta$ (TGF- $\beta$ ), tumor necrosis factor a (TNF-a) and interleukin-8 (IL-8). These factors are responsible for proliferation and migration of endothelial cells and thus lead to increase tumor angiogenesis. ${ }^{7,22}$

Mast cells are also rich sources of proteases, specifically tryptase and chymase, which by their proteolytic activities, directly degrade extracellular matrix components or release matrix associated growth factor, thereby indirectly stimulating angiogenesis and facilitating invasion and metastasis by extracellular matrix remodeling. Matrix metalloproteinases (MMP-2 and MMP-9) are also produced by mast cells and may contribute to extracellular matrix degradation. Thus, mast cells may have an impact on both primary tumor development and subsequent tumor progression and metastasis. Mast cells also contribute to tumor growth through secreting immunosuppressant like histamine, tumor necrosis factor- $\alpha$, transforming growth factor $-\beta$ and interleukin-10. ${ }^{14}$

Therefore the aim of the study was to assess the number of mast cell in well differentiated oral squamous cell carcinoma in contrast to normal oral mucosa. It will provide valuable information about the role of mast cell in progression of tumor. It may also help to develop certain therapeutic methods that target mast cell for the adjuvant treatment of tumor. 


\section{Methodology}

This was a cross-sectional observational study carried out at the Department of Pathology, Mymensingh Medical College, Mymensingh. The sample size was 66. The study population was all the tissue samples (66) diagnosed as oral squamous cell carcinoma received at the Department of Pathology of Mymensingh Medical College during specified time duration. All these specimens were sectioned, stained and studied in Department of Pathology MMC. 10 fresh oral tissue samples were collected from unidentified postmortem case with permission of Department of Forensic Medicine, MMC. These samples were taken from different regions of oral cavity (gingiva, buccal mucosa and tongue). They were considered as control to see the number of mast cells.

The 66 biopsy tissues and 10 postmortem tissues were fixed in 10\% formalin and kept for overnight fixation. Next day, the tissues were examined during grossing and were embedded accordingly. Tissue processing was performed manually following standard protocol for paraffin embedding. The paraffin blocks were sectioned with a rotary manual microtome at 5 micrometer thickness. From each paraffin blocks two glass slides were made. After deparaffinization with xylene the slides were rehydrated with decreasing graded alcohol. Then one slide was stained with routine Haematoxylin and Eosin (H\&E) stain. Another slide was stained with Toluidine blue stain.

Slides of all cases were examined and graded as well-differentiated carcinoma according to Anneroth's grading system.

\section{Interpretation of special stain for mast cell:}

As mast cell cytoplasm contains granules (metachromatic) composed of heparin, histamine etc. Toluidine blue stains mast cell red purple and the background stains blue. Based on intensity of metachromasia mast cells were categorized into 2 groups-
1. Intact mast cells exhibiting intense metachromasia and dense granules obscuring the nucleus.

2. Partially degranulated mast cells with less intense metachromasia and a clear outline of nucleus. ${ }^{13}$

\section{Observation of mast cell number:}

For determination of mast cell density, the stained sections were screened at low power (100X) to identify the areas of the hot spots (areas with largest number of mast cell). Mast cell counting was performed at high power (400X) magnification in three randomly choosen fields in the hot spot areas. The mast cell count was expressed as the number of mast cells per high power field (n/hpf). The average figure which was obtained in the hot spot fields, was considered as the mast cell number for a given case. ${ }^{15,16}$ Mast cells number was observed both in control and OSCC cases (Figures 03, 04).

\section{Results}

This cross sectional study was performed to evaluate the significance of mast cell degranulation in oral SCC and to assess the number of mast cell infiltration in well differentiated oral SCC. In this study age of the patients varied from 24-80 years. Out of 66 cases 25 (37.9\%) samples belonged to age 51-60 years and mean \pm SD age was $53.41 \pm 10.35$ years (Table 01). Total $69.7 \%$ patients were male with a male female ratio 2.3:1(Figure 01). Regarding site, $40.9 \%$ cases were from tongue, $24.2 \%$ from buccal mucosa, $13.6 \%$ from gingiva, $10.6 \%$ from palate, $4.5 \%$ from floor of the mouth, $4.5 \%$ from lip and $1.5 \%$ from retro-molar area (Figure 02). In this study smoking history was assessed. No female patient had history of smoking but among male, $69.6 \%$ patient had smoking habit (Table 02). In the present study, number of mast cell infiltration was counted. The mean \pm SD number of mast cells was $3.28 \pm 1.21$, whereas in control oral 
tissue it was $0.44 \pm 0.19$. The $p$ value was found to be highly significant $(p<0.001)$ (Table 03).

Table 01: Distribution of the patients according to age $(n=66)$

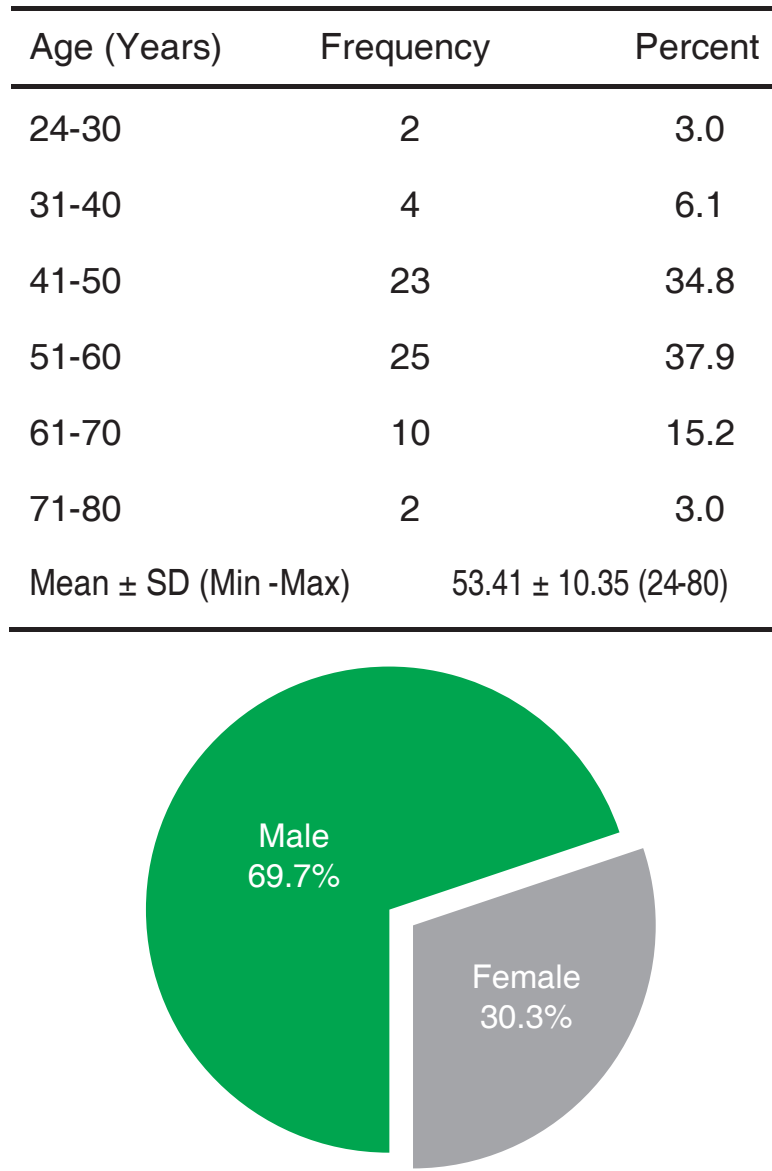

Figure 01: Distribution of the patients according to sex

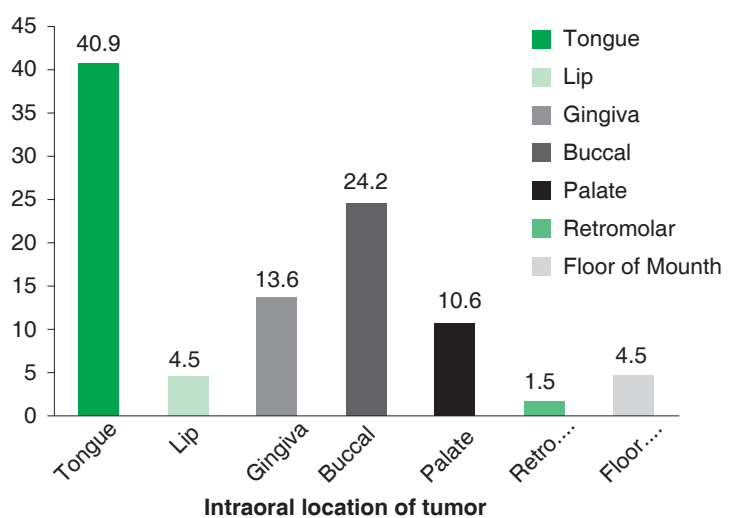

Figure 02: Distribution of the patients according to intraoral location of tumor $(n=66)$

Table 02: Distribution of the patients according to smoking habit $(n=46)$

\begin{tabular}{lcc}
\hline Smoking habit & Frequency & Percent \\
\hline Present & 32 & 69.6 \\
Absent & 14 & 30.4 \\
Total & 46 & $\mathbf{1 0 0 . 0}$ \\
$\begin{array}{l}\text { Duration of smoking } \\
\text { (years) }\end{array}$ & & \\
Mean \pm SD (Min-Max) & $35.79 \pm 11.24(10-65)$
\end{tabular}

Table 03: Distribution of the patients according to number of mast cell by groups

\begin{tabular}{lccl}
\hline Number of mast cell & $\begin{array}{c}\text { Case } \\
(\mathbf{n}=66)\end{array}$ & $\begin{array}{c}\text { Gontrol } \\
(\mathbf{n}=3)\end{array}$ & p value \\
\cline { 2 - 3 } & $3.28 \pm 1.21$ & $0.44 \pm 0.19$ & \\
Mean \pm SD & $1.00-7.33$ & $0.33-0.66$ & \\
Min-Max & 3.00 & 0.33 & $<0.001^{\mathrm{a}}$ \\
Median &
\end{tabular}

${ }^{a}$ Mann-Whitney $U$ test was done to measure the level of significance 


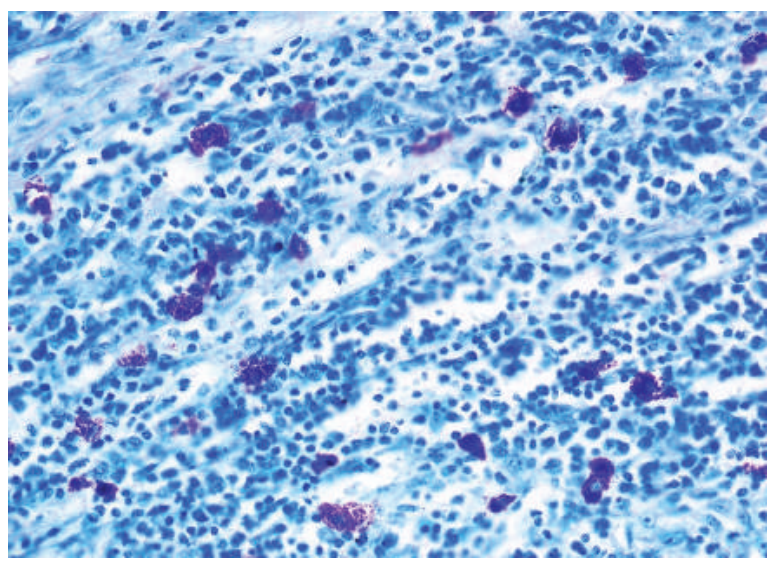

Figure 03: Photomicrograph showing mast cell in well differentiated squamous cell carcinoma (Case 26, Toluidine blue stain $\times 400$ )

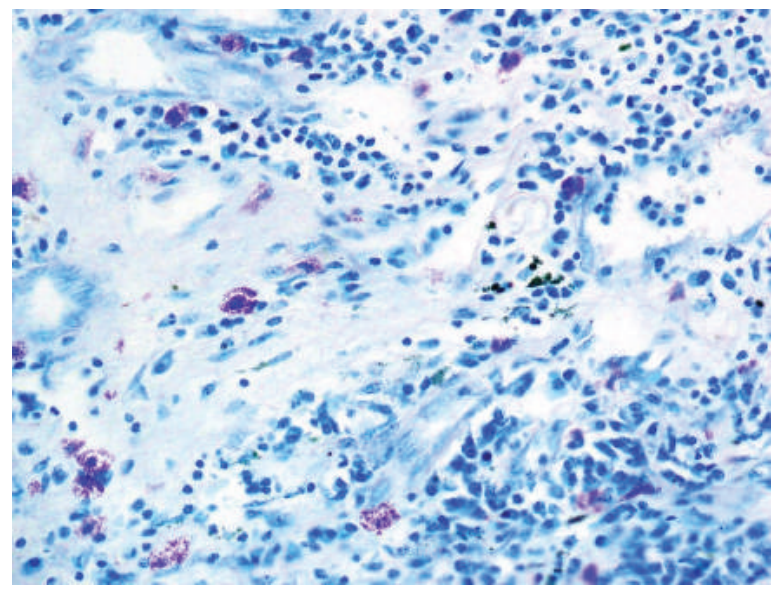

Figure 04: Photomicrograph showing mast cell in well differentiated squamous cell carcinoma (Case 41, Toluidine blue stain $\mathrm{x} 400$ )

\section{Discussion}

Oral squamous cell carcinoma (OSCC) is one of the most common cancers in Indian subcontinent. It continues to impose a serious threat to the oral health. In spite of vast advancement in the field of cancer research, availability of sophisticated diagnostic techniques and improved therapeutic options, prognosis of such patients is still remains very poor. This is probably due to unpredictable behavior of these tumors which shows a variable aggressiveness independent of clinico-pathologic and histological grading.
The surrounding stroma of tumor is gaining attention due to infiltration of many inflammatory cells including the mast cells. Mast cells are mobile secretory cells containing granules. These cells are distributed around the microvascular endothelium in the oral mucosa and dental pulp. Apart from the role of mast cells in maintenance of homeostasis and inflammation, their association with tumors has been described recently. In several malignancies, mast cell density has been found to correlate with angiogenesis, increased risk of metastasis and poor prognosis. As oral SCC is associated with chronic inflammation in adjacent connective tissue, immune reaction and angiogenesis, there is a need to evaluate the role of mast cells in it. This cross sectional study was carried out with an aim to evaluate the significance of mast cells degranulation in development of oral SCC and to compare the number and distribution of mast cell among well differentiated oral SCC.

In this study it was observed that age of the patients varied from 24-80 years. Out of 66 patients 25 (37.9\%) samples belonged to age 51-60 years and mean \pm SD age was $53.41 \pm 10.35$ years. Similarly in Pakistan other authors found in their study that the median age was $54.30 \pm 1.561$ years in a range of $32-80$ years. ${ }^{16}$ In India, another study showed age distribution ranged between 25-72 years. ${ }^{23}$ Some other investigator found a little higher age distribution. In Norway, a group of authors found most of the patient aged $>60$ years. ${ }^{24}$ Similarly in Brazil, authors found most of the patient $(66 \%)$ aged $\leq 65$ years. ${ }^{25}$ In Greece, study showed average age $60.38 \pm 14.99$ years with a range of $26-87$ years. ${ }^{26}$ In Germany, authors found mean age 60.81 \pm 11.98 years. ${ }^{27}$ These age differences may be due to different races with different life expectancy.

In the present study, it was observed that $69.7 \%$ patients belong to male with a male-female ratio 2.3:1. Similar findings were observed in some other studies. Some authors 
found most of the patients were male with a male female ratio 2:1.26,28 Another author also observed male predominance with a male female ratio $1.81: 1 .{ }^{24}$

In the current study, $40.9 \%$ cases were from tongue, $24.2 \%$ from buccal mucosa, $13.6 \%$ from gingiva, $10.6 \%$ from palate, $4.5 \%$ from floor of the mouth, $4.5 \%$ from lip and $1.5 \%$ from retro-molar area. Another author also found most of the cases were from tongue $(38.88 \%)$, with buccal mucosa being the next most common site $(27.77 \%) .{ }^{23}$ Other groups of authors found tongue (42\%) as most common site followed by floor of the mouth (24\%). ${ }^{25}$ Some found buccal mucosa as most common site (32.4\%) followed by tongue $(21.6 \%)$, palate and lip (10.8\%) and gingiva (5\%). ${ }^{17}$ Some authors observed that, floor of the mouth (40\%) was the most common site followed by tongue (27\%) and gingiva (20.96\%). ${ }^{24}$ Another group of authors had found almost same result. ${ }^{27}$ So tongue and buccal mucosa may be the most common site affected by oral squamous cell carcinoma.

The oral mucosa undergoes various reversible and irreversible changes to carcinogens. These changes have been observed in the epithelial cells as well as in the connective tissue. The changes in the connective tissue have been evident by the occurrence of an inflammatory component as well as an increase in vascularity. Mast cells are one of the inflammatory components involved in process of angiogenesis. In normal oral tissue mast cells have been found to be present in the connective tissue of gingiva, tongue and lining mucosa although in very low densities. ${ }^{23}$

So it is important to know the pattern of distribution of mast cells in normal oral mucosa and in oral SCC. In the present study toluidine blue was used to detect mast cells. Although various immunohistochemical methods can be used, toluidine blue is simple, less time consuming and inexpensive. Moreover, mast cells are easily recognized in light microscopy by this stain as they filled with metachromatic cytoplasmic granules. To see the number of mast cells in normal oral mucosa, 10 fresh oral tissue samples were collected from unidentified postmortem cases. These samples were considered as control. Among ten cases only three shows distribution of mast cells in the lamina propria, and the average number of mast cells was $1.33 \pm 0.57$.

In the present study, number of mast cells infiltration was evaluated. The mean \pm SD number of mast cells was $3.28 \pm 1.21$, whereas in control oral tissue it was $0.44 \pm$ 0.19 . The $p$ value was found to be highly significant $(p<0.001)$. Similarly in Pakistan, a group of authors found similar results. The number of mast cells also increased significantly in OSCC than normal oral tissue $(P=0.001) .{ }^{16}$

\section{Conclusion}

The design of current study was intended to figure out the role of mast cell in oral SCC. We also searched the number of mast cell in well differentiated oral SCC. By an extensive review of literature we found that mast cell is closely related to tumoriogenesis and its number increased in oral SCC. Our experiment revealed the similar kind of statement. The number of mast cell is highly increased in all cases of well-differentiated oral SCC than normal. So, according to our observation mast cell can be a good cellular indicator of tumoriogenesis.

\section{References}

1. Shah, J.P. and Gil, Z., 2009. Current concepts in management of oral cancer-surgery. Oral oncology, 45(4-5), pp.394-401.

2. Bagan, J., Sarrion, G. and Jimenez, Y., 2010. Oral cancer: clinical features. Oral oncology, 46(6), pp.414-417. 
3. Feller, L. and Lemmer, J., 2012. Oral squamous cell carcinoma: epidemiology, clinical presentation and treatment. Journal of cancer therapy, 3(04), p.263.

4. Rao, S.V.K., Mejia, G., Roberts-Thomson, K. and Logan, R., 2013. Epidemiology of oral cancer in Asia in the past decade-an update (2000-2012). Asian Pacific journal of cancer prevention, 14(10), pp.5567-5577.

5. Rahman, Q.B., 2016. Oral cancer: One of the leading malignancies in Bangladesh. Bangabandhu Sheikh Mujib Medical University Journal, 7(2), pp.75-76.

6. Hussain, S.M.A., 2013. Comprehensive update on cancer scenario of Bangladesh. South Asian journal of cancer, 2(4), p.279.

7. Ribatti, D. and Crivellato, E., 2012. Mast cells, angiogenesis, and tumour growth. Biochimica et Biophysica Acta (BBA)-Molecular Basis of Disease, 1822(1), pp.2-8.

8. Rigoni, A., Colombo, M.P. and Pucillo, C., 2015. The role of mast cells in molding the tumor microenvironment. Cancer microenvironment, 8(3), pp.167-176.

9. Rajabi, P., Bagheri, A. and Hani, M., 2017. Intratumoral and peritumoral mast cells in malignant melanoma: an immunohistochemical study. Advanced biomedical research,

10. Leporini, C., Ammendola, M., Marech, I., Sammarco, G., Sacco, R., Gadaleta, C.D., Oakley, C., Russo, E., De Sarro, G. and Ranieri, G., 2015. Targeting mast cells in gastric cancer with special reference to bone metastases. World Journal of Gastroenterology: WJG, 21(37), p.10493.

11. Grizzi, F., Franceschini, B., ChirivaInternati, M., Liu, Y., Hermonat, P.L. and Dioguardi, N., 2003. Mast cells and human hepatocellular carcinoma. World Journal of Gastroenterology: WJG, 9(7), p.1469.

12. Sari, A., Calli, A., Cakalagaoglu, F., Altınboga, A.A. and Bal, K., 2012. Association of mast cells with microvessel density in urothelial carcinomas of the urinary bladder. Annals of diagnostic pathology, 16(1), pp.1-6.

13. Zaidi, M.A. and Mallick, A.K., 2014. A study on assessment of mast cells in oral squamous cell carcinoma. Annals of medical and health sciences research, 4(3), pp.457-460.

14. Ramsridhar, S. and Narasimhan, M., 2016. Immunohistochemical evaluation of mast cells in leukoplakia and oral Squamous cell carcinoma. Journal of clinical and diagnostic research: JCDR, 10(8), p.ZC100.

15. Cheema, V.S., Ramesh, V. and Balamurali, P.D., 2012. The relevance of mast cells in oral squamous cell carcinoma. Journal of clinical and diagnostic research: JCDR, 6(10), p.1803.

16. Tahir, A., Nagi, A., Ullah, E. and Janjua, O., 2013. The role of mast cells and angiogenesis in well-differentiated oral squamous cell carcinoma. Journal of Cancer Research and Therapeutics, 9(3), pp.387-387.

17. Kalra, M., Rao, N., Nanda, K., Rehman, F., Girish, K.L., Tippu, S. and Arora, A., 2012. The role of mast cells on angiogenesis in oral squamous cell carcinoma. Medicina oral, patologia oral y cirugia bucal, 17(2), p.190.

18. Mohtasham, N., Babakoohi, S., Salehinejad, J., Montaser-Kouhsari, L., Shakeri, M.T., Shojaee, S., Sistani, N.S. and Firooz, A., 2010. Mast cell density and angiogenesis in oral dysplastic epithelium and low-and high-grade oral squamous cell carcinoma. Acta Odontologica Scandinavica, 68(5), pp.300-304.

19. Soucek, L., Lawlor, E.R., Soto, D., Shchors, K., Swigart, L.B. and Evan, G.I., 2007. Mast cells are required for angiogenesis and macroscopic expansion of Myc-induced pancreatic islet tumors. Nature medicine, 13(10), p.1211.

20. Rojas, I.G., Spencer, M.L., Martinez, A., Maurelia, M.A. and Rudolph, M.I., 2005. 
Characterization of mast cell subpopulations in lip cancer. Journal of oral pathology \& medicine, 34(5), pp.268-273.

21. Tomita, M., Matsuzaki, Y. and Onitsuka, T., 1999. Correlation between mast cells and survival rates in patients with pulmonary adenocarcinoma. Lung Cancer, 26(2), pp.103-108.

22. Huang, B., Lei, Z., Zhang, G.M., Li, D., Song, C., Li, B., Liu, Y., Yuan, Y., Unkeless, J., Xiong, H. and Feng, Z.H., 2008. SCF-mediated mast cell infiltration and activation exacerbate the inflammation and immunosuppression in tumor microenvironment. Blood, 112(4), pp.1269-1279.

23. Veda, M.V., 2015. Mast cells and angiogenesis in oral epithelial dysplastic lesions and oral squamous cell carcinoma. International Journal of Medical Research and Health Sciences, 4(1), pp.46-52.

24. Attramadal, C.G., Kumar, S., Gao, J., Boysen, M.E., Halstensen, T.S. and Bryne, M., 2016. Low mast cell density predicts poor prognosis in oral squamous cell carcinoma and reduces survival in head and neck squamous cell carcinoma. Anticancer research, 36(10), pp.5499-5506
25. Oliveira-Neto, H.H., Leite, A.F., Costa, N.L., Alencar, R.C., Lara, V.S., Silva, T.A., Leles, C.R., Mendonça, F.E. and Batista, A.C., 2007. Decrease in mast cells in oral squamous cell carcinoma: possible failure in the migration of these cells. Oral oncology, 43(5), pp.484-490.

26. Michailidou, E.Z., Markopoulos, A.K. and Antoniades, D.Z., 2008. Mast cells and angiogenesis in oral malignant and premalignant lesions. The open dentistry journal, 2, p.126

27. Brockmeyer, P., Hemmerlein, B., Kruppa, J., Kauffmann, P., Tröltzsch, M., Schliephake, H. and Gruber, R.M., 2015. The time interval between primary surgery and adjuvant therapy determines prognosis of oral squamous cell carcinomas. Oral oncology, 51(11), pp 82-e85.

28. Sharma, B., Sriram, G., Saraswathi, T.R. and Sivapathasundharam, B., 2010. Immunohistochemical evaluation of mast cells and angiogenesis in oral squamous cell carcinoma. Indian Journal of Dental Research, 21(2), p.260. 